\title{
REFORMA Y REHABILITACIÓN DE LA CÁMARA DE COMERCIO E INDUSTRIA DE GUADALAJARA/ESPAÑA
}

\author{
(REFORM AND REHABILITATION OF THE CHAMBER OF COMMERCE AND INDUSTRY IN \\ GUADALAJARA/SPAIN)
}

Valentín Quintas y José Augusto Vizcaíno, Arquitectos; Mariola del Santo y Javier Bonilla, Colaboradores; José Luis González-Madroño y Javier Polo, Aparejadores

Constructor: VIESAN, S.L.

ESPAÑA

Fecha de recepción: 25-IV-97

$128-71$

\section{RESUMEN}

En este articulo se describen las obras de rehabilitación de un edificio del siglo XVIII -con vestigios de otro del siglo $X V I-$ reformado en el siglo XLX. Se reconstruyeron las dos fachadas, el patio y la escalera principal recuperando su aspecto original. Se utilizó una estructura mixta de

hormigón-acero para conseguir la iluminación natural y los espacios libres que necesita un edificio administrativo.

\section{SUMMARY}

In this paper the reform of a 18th century building, with 16th century vestiges, and a 19th century reconstruction, is described. The two façades, the courtyard and the main stairs were refit into its original state. The free spaces and the natural light that an administrative building needs were obtained by means of a composite concrete-steel structure.

\section{Antecedentes}

La "Casa de los Torres" en Guadalajara es un edificio del siglo XVIII, construido sobre otro del siglo XVI del que quedaban, como vestigios, los restos de un forjado de madera reutilizado y una serie de columnas de piedra. Posteriormente, la familia Torres le añadió un portal blasonado de piedra, manteniendo la antigua puerta de madera, y rehizo la escalera y el patio del siglo XVIII, haciéndoles perder su antiguo aspecto.

A principios de este siglo sufrió una nueva reforma debida al arquitecto Benito Ramón Cura, que proyectó la actual fachada a la calle Mayor. Ya en nuestros días, perdió su uso residencial al ocuparse la planta baja con locales comerciales, que eliminaron la fachada de Ramón Cura hasta la planta principal y transformarse, esta planta, en la Sede de la Cámara de Comercio de Guadalajara. En 1992 sufrió un incendio que destruyó parte de la cubierta, por lo que la Cámara de Comercio, presidida por Ramón Silgo, decidió convocar un Concurso para reconstruir y rehabilitar totalmente el edificio. El resultado de ese Concurso es la obra que se describe a continuación.

\section{El proyecto}

Utilizando los antiguos planos de Ramón Cura, se decidió darle a la fachada de la calle Mayor su aspecto original, reconstruyendo la planta baja y las molduras que habían desaparecido en las sucesivas reformas. La fachada posterior permitía adivinar que estuvo formada por dos galerías con un cuerpo central, muy típicas de Guadalajara, por lo que, tambíen, se le volvió a dar su aspecto original. Se reutilizaron las columnas del XVI para soportar la galería y las viguetas de la misma época para reconstruir los forjados originales. En el patio se volvieron a abrir los huecos tapiados, se cerraron los añadidos en el siglo pasado, reconstruyéndose la cornisa de canecillos que había desaparecido sustituida por una de yeso. La escalera principal se encontraba totalmente-desfigurada, sólo quedaban, como restos, unos óculos elípticos que indicaban que había estado cubierta por una bóveda con sus correspondientes pechinas y su trazado. Se le ha reconstruido, dándole el aspecto que debía tener en el siglo XVIII.

Los interiores del edificio presentaban un aspecto caótico debido a las sucesivas reformas y cambios de uso. Se decidió dejar unos espacios tan diáfanos y luminosos como fuera posible, para poder darle el uso flexible que exigía un edificio administrativo. Para que toda la planta principal tuviese iluminación natural se proyectaron una serie de huecos en diente de sierra orientados al Norte, respetando el trazado original de la cubierta. El patio se cubrió con una cubierta de policarbonato ventilada, que ha permitido transformar el efecto invernadero en una ventilación natural en verano. 


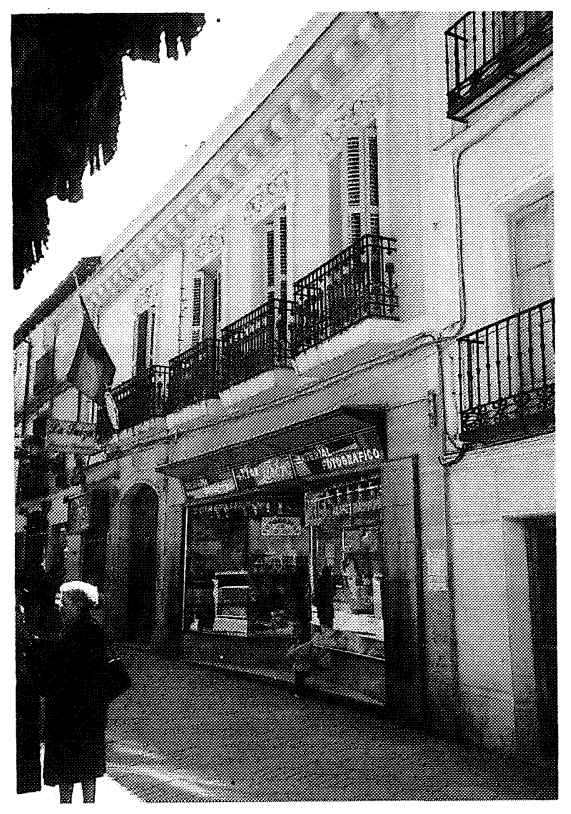

Fachada c/Mayor. Estado primitivo.

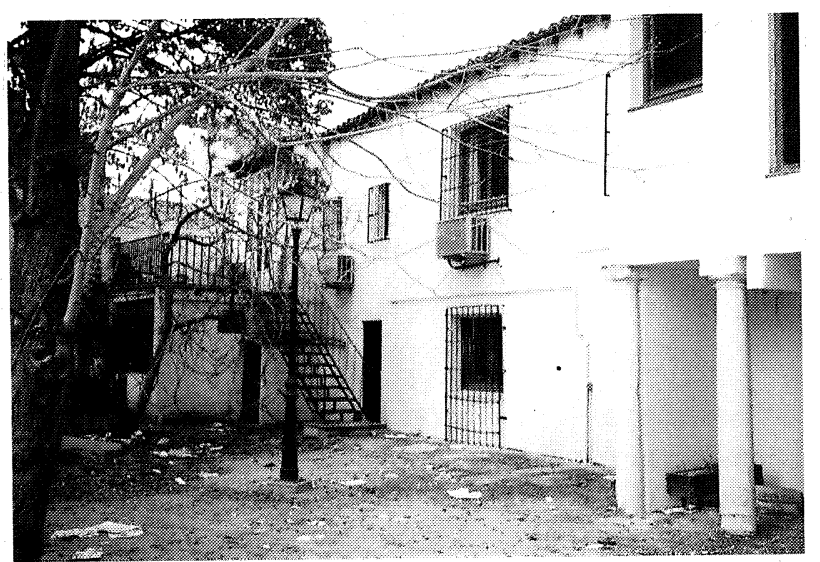

Fachada posterior. Estado primitivo.

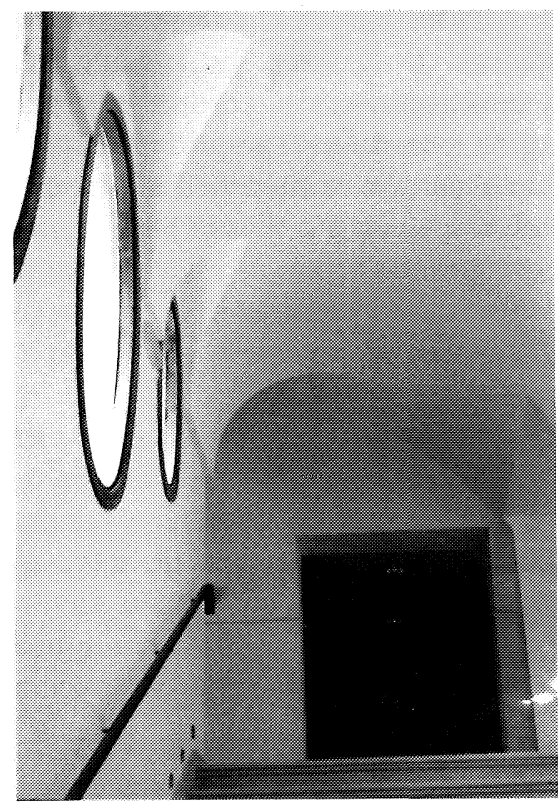

Escalera.

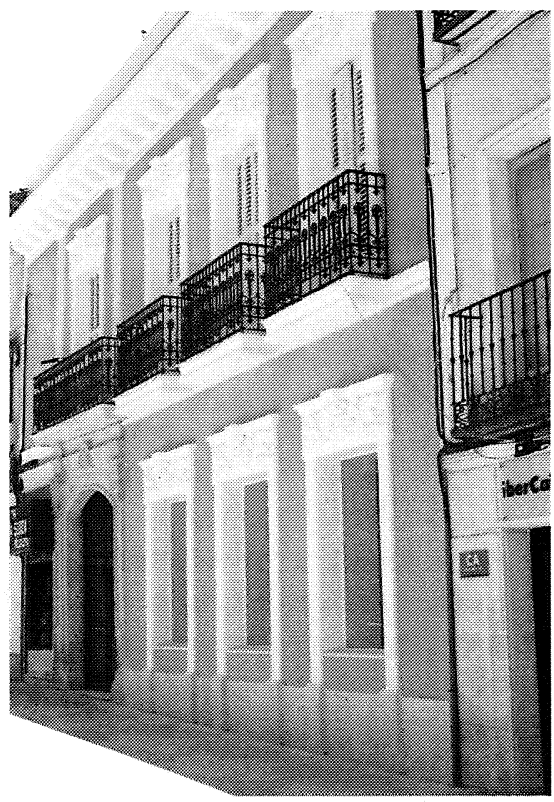

Fachada c Mayor. Estado actual

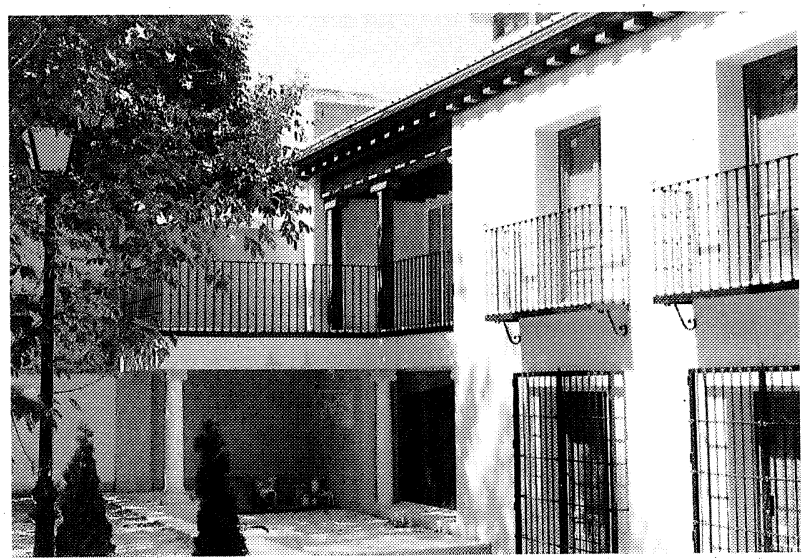

Fachada posterior. Estado actual.

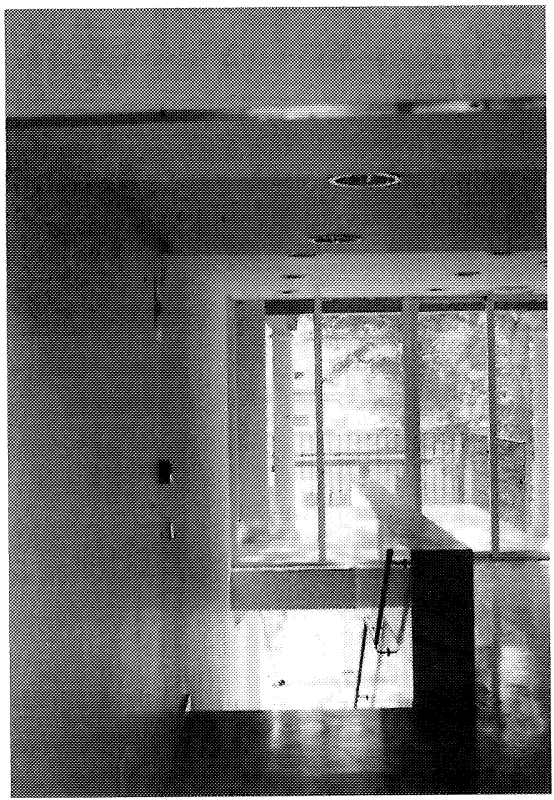

Interior. 


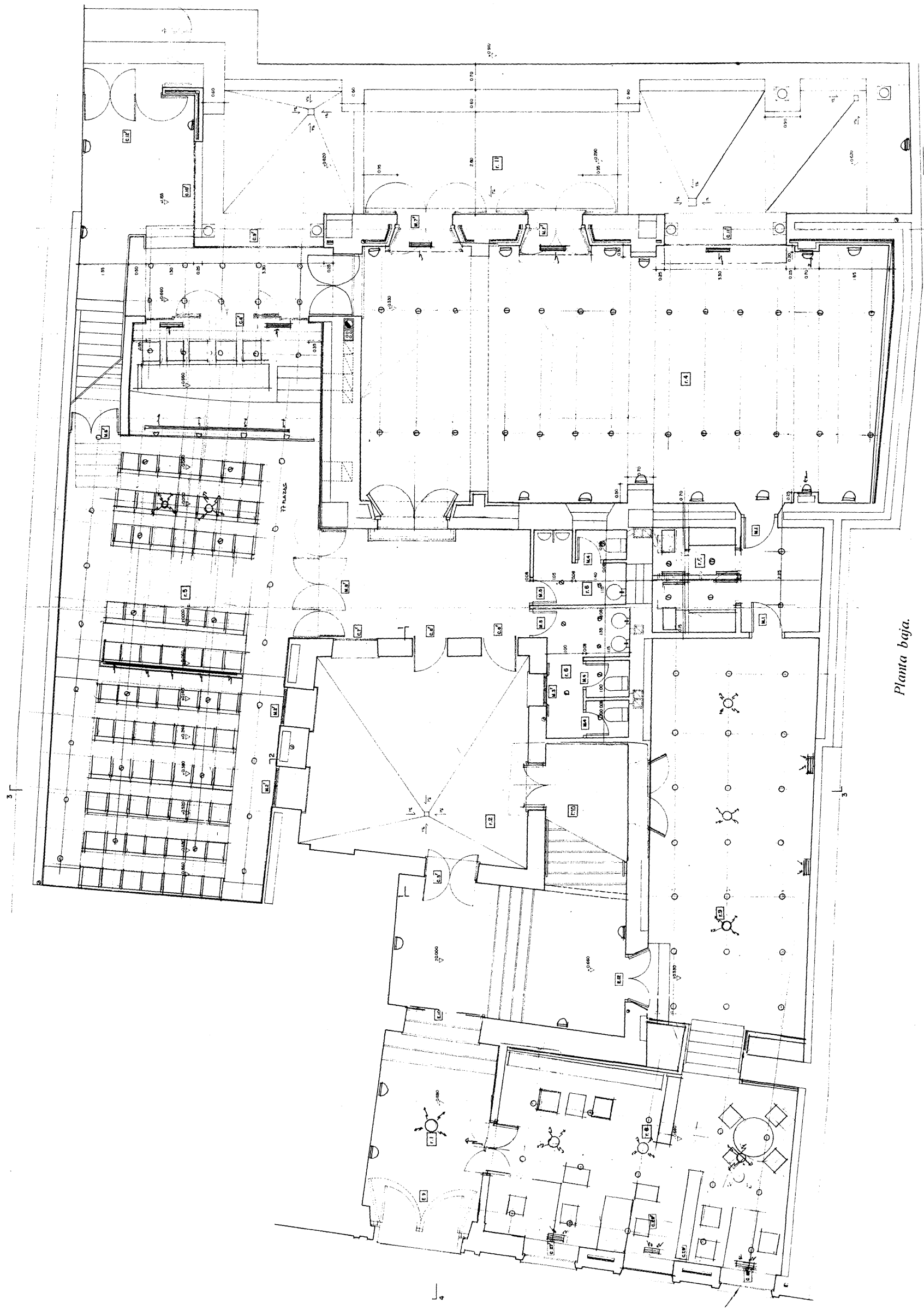




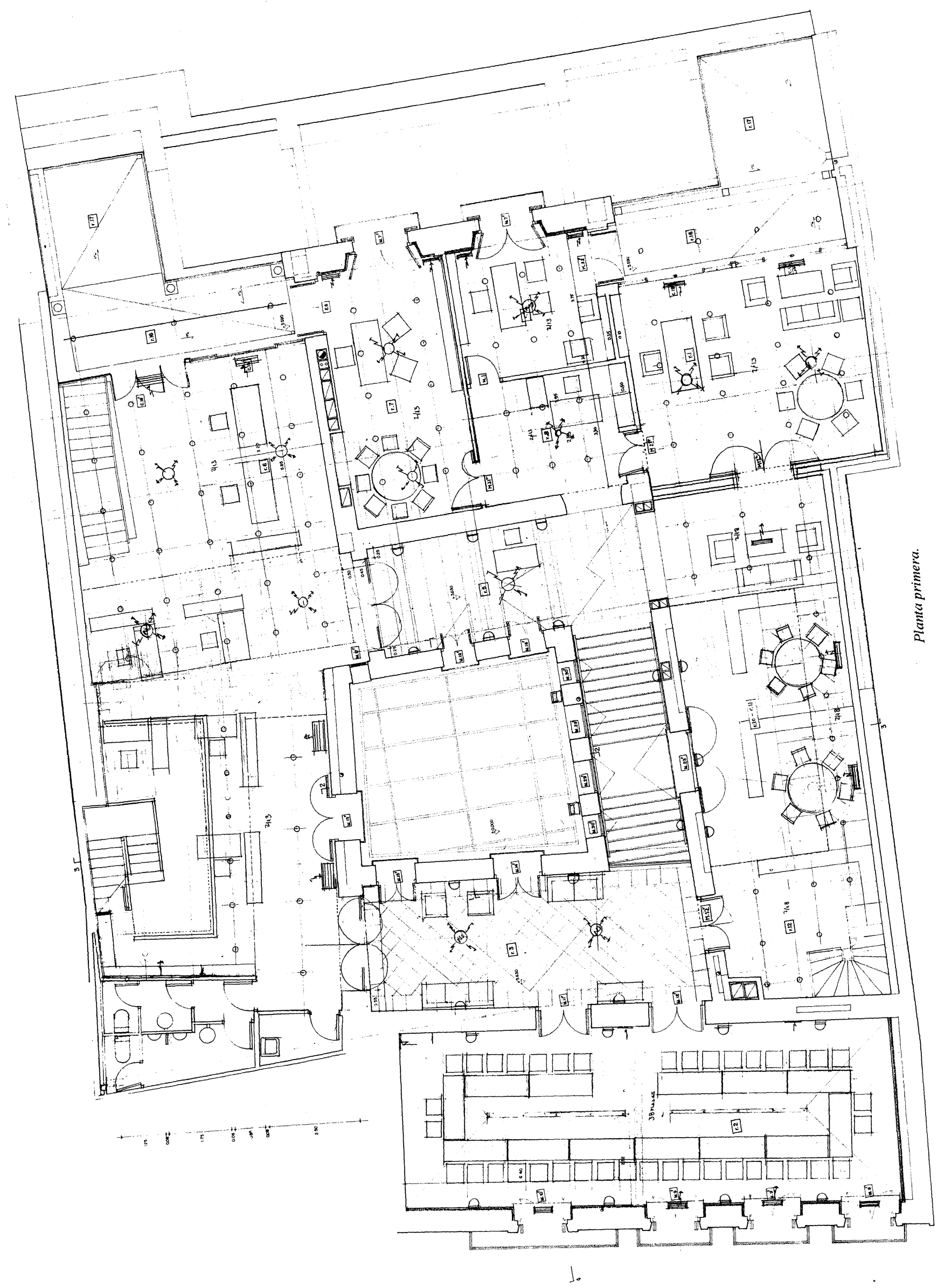




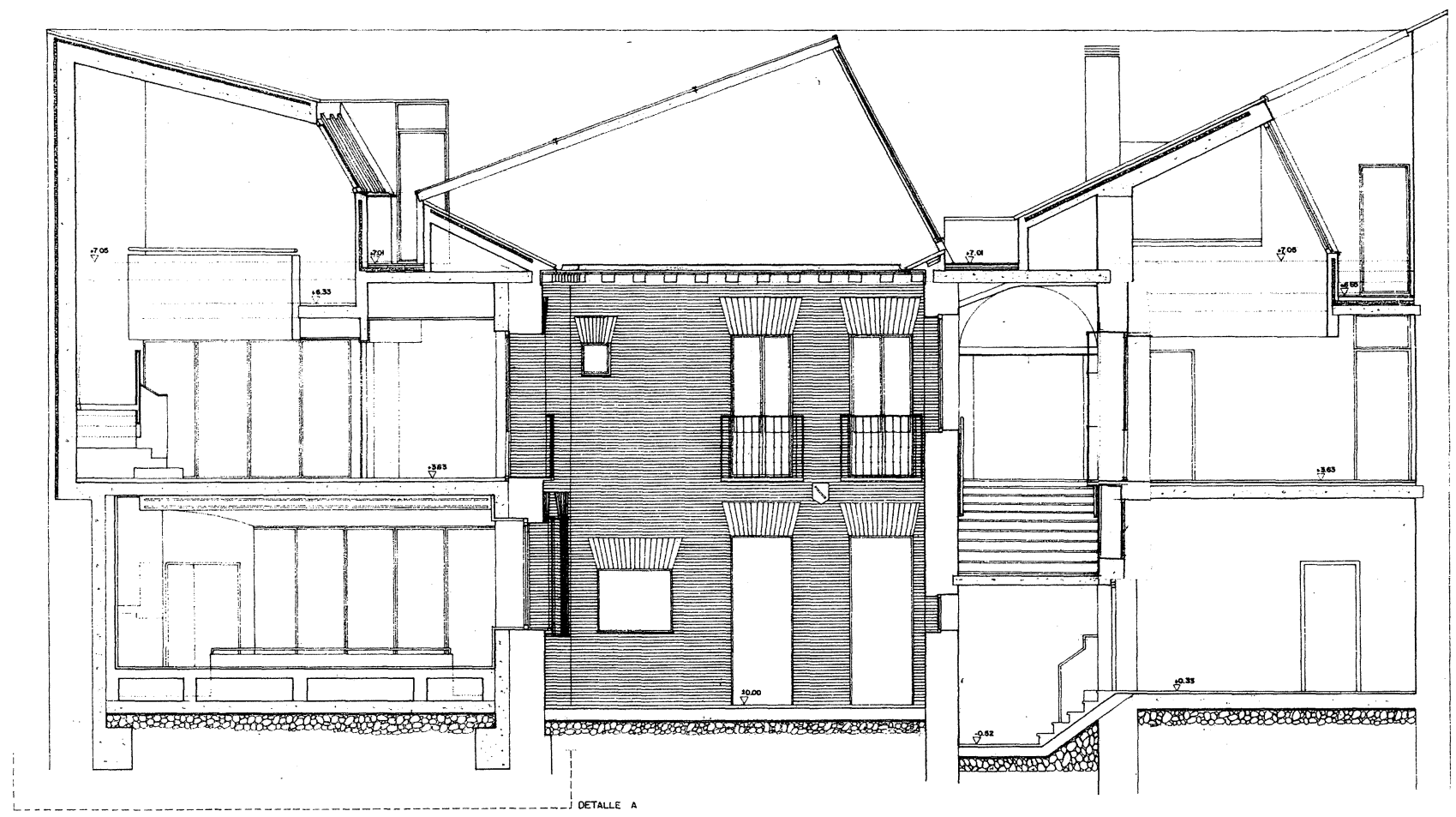

Sección.

\section{La estructura}

Con objeto de que el edificio tuviese las necesarias condiciones de aislamiento acústico se proyectó la estructura de las plantas baja y principal de losa de hormigón armado maciza. Como es bien conocido -aunque muchas veces ignorado- una losa es extraordinariamente rígida y resistente si es de planta cuadrada o circular y está apoyada en muros. Si está apoyada en pilares, o es de planta rectangular alargada -como era el caso en este edificio- su rigídez y resistencia es sólo ligeramente superior a la de un forjado convencional y, por lo tanto, deben dársele los cantos que se presciben para los forjados y no los de $1 / 40$ de la luz que permite la norma para losas, pensada precisamente para placas cuadradas o circulares, o sensiblemente cuadradas o circulares y apoyadas en muros. Como el canto de una losa maciza no debe sobrepasar los $24 \mathrm{~cm}$, pues de otra forma su peso propio empezaría a superar, con mucho, la suma de cargas y sobrecargas, la luz de unalosa rectangular alargada raramente puede superar los $7 \mathrm{~m}$, en el lado corto, que es en el sentido en el que realmente trabaja. Hacer una losa aligerada para superar esas luces con más canto, le hacía perder las propiedades acústicas que se buscaban. En las zonas en que, por la distribución del edificio, se necesitaban luces mayores, se reforzó la losa con perfiles metálicos o con celosías metálicas, de forma que la losa formaba, en la zona en contacto con las vigas o celosías, el bloque de compresión y aquéllas, el de tracción. Se realizarón, pues, vigas y celosías mixtas hormigón-acero con menos canto del que necesitarían aisladas.
La cubierta -que no necesitaba ningún aislamiento acústico- se realizó con un forjado convencional inclinado, apoyado en la cumbrera en una jácena longitudinal que, a su vez, se apoyaba en unas formas inclinadas, con tirantes embebidos en las losas de hormigón.

De esta forma las reacciones de los forjados eran verticales, evitando los empujes continuos que normalmente son difíciles de controlar.

\section{La construcción}

Se intentó, en lo posible, que existiese un aislamiento térmico perfecto. Para ello seaislaron todos los paramentos horizontales con $4 \mathrm{~cm}$ de poliestireno expandido y una cámara de aire de $4 \mathrm{~cm}$.

En la cubierta se colocó una capa continua de $4 \mathrm{~cm}$ de poliestireno expandido, sobre la que se dispuso una familia de rastreles embebida en otra capa de $4 \mathrm{~cm}$ de mortero de cemento armada con tela de gallinero, a la que iba clavada una cubierta de "onduline". Sobre ella se colocó la teja acopiada del antiguo tejado, más parte de teja tomada de otros derribos. De esta forma el aislamiento formaba una capa continua sin puentes térmicos.

Las fachadas se revistieron con un enfoscado de mortero bastardo, sobre el que se tendió un revoco a la cal, liso. 

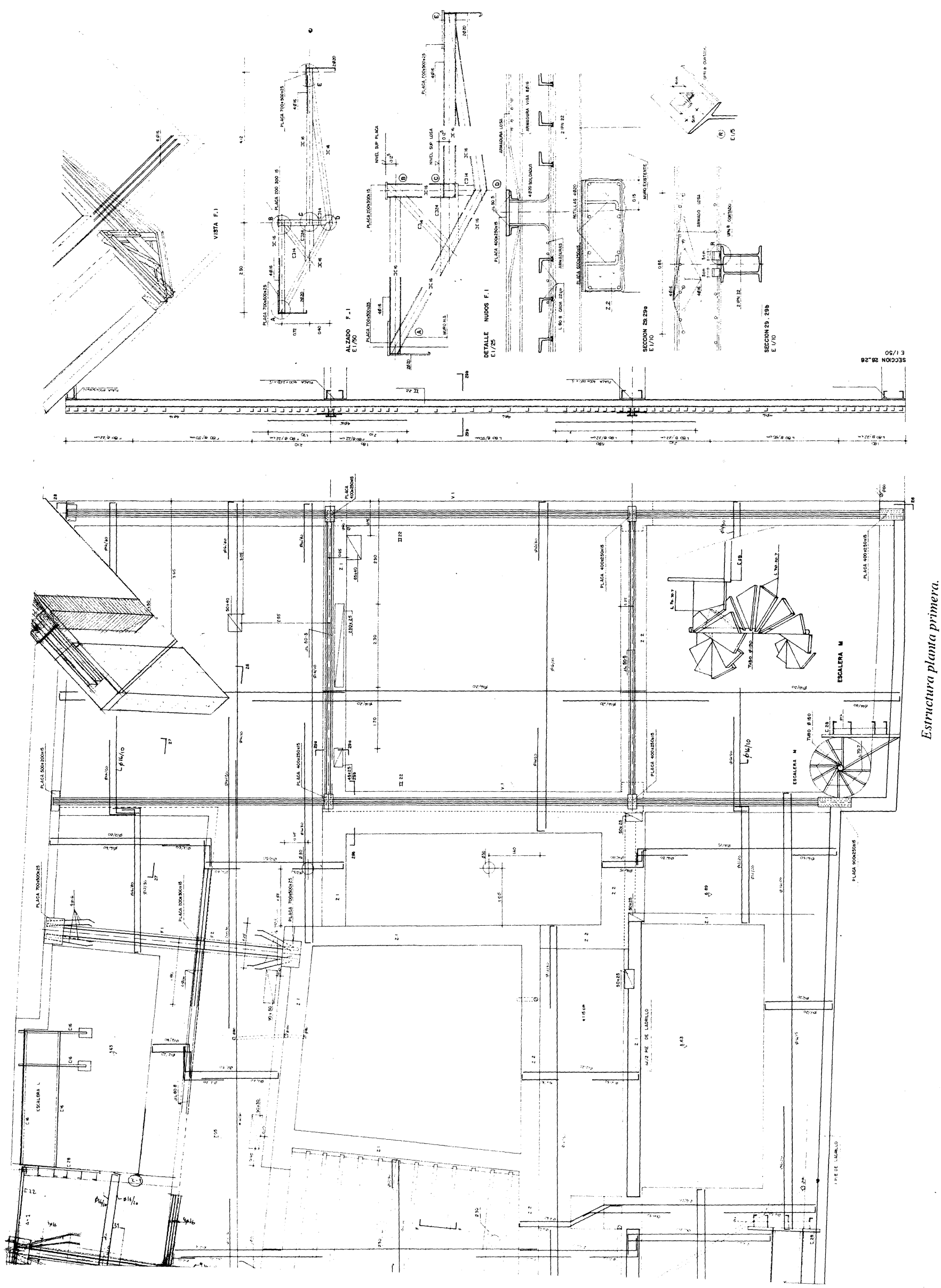

(c) Consejo Superior de Investigaciones Científicas Licencia Creative Commons 3.0 España (by-nc) 

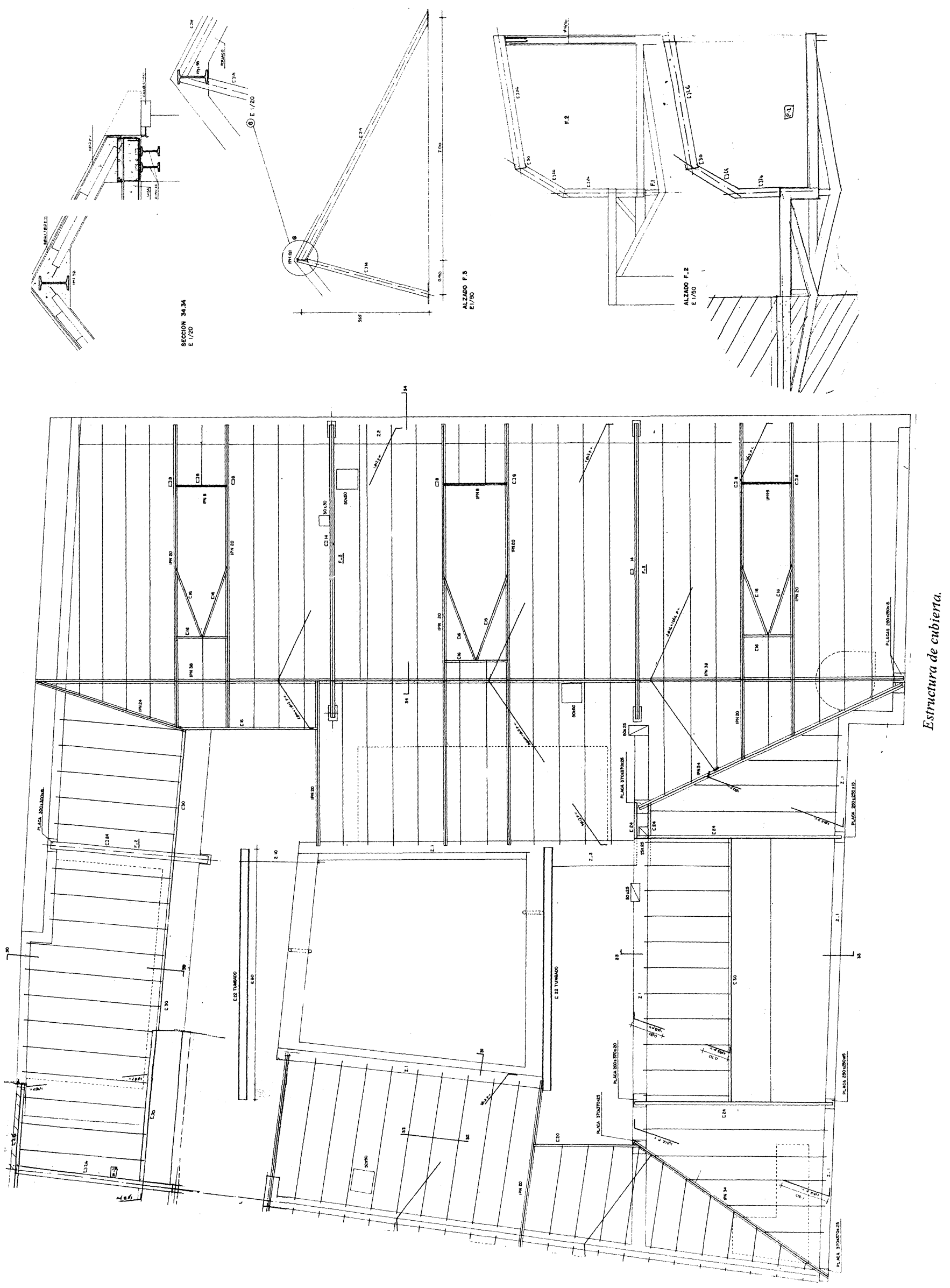

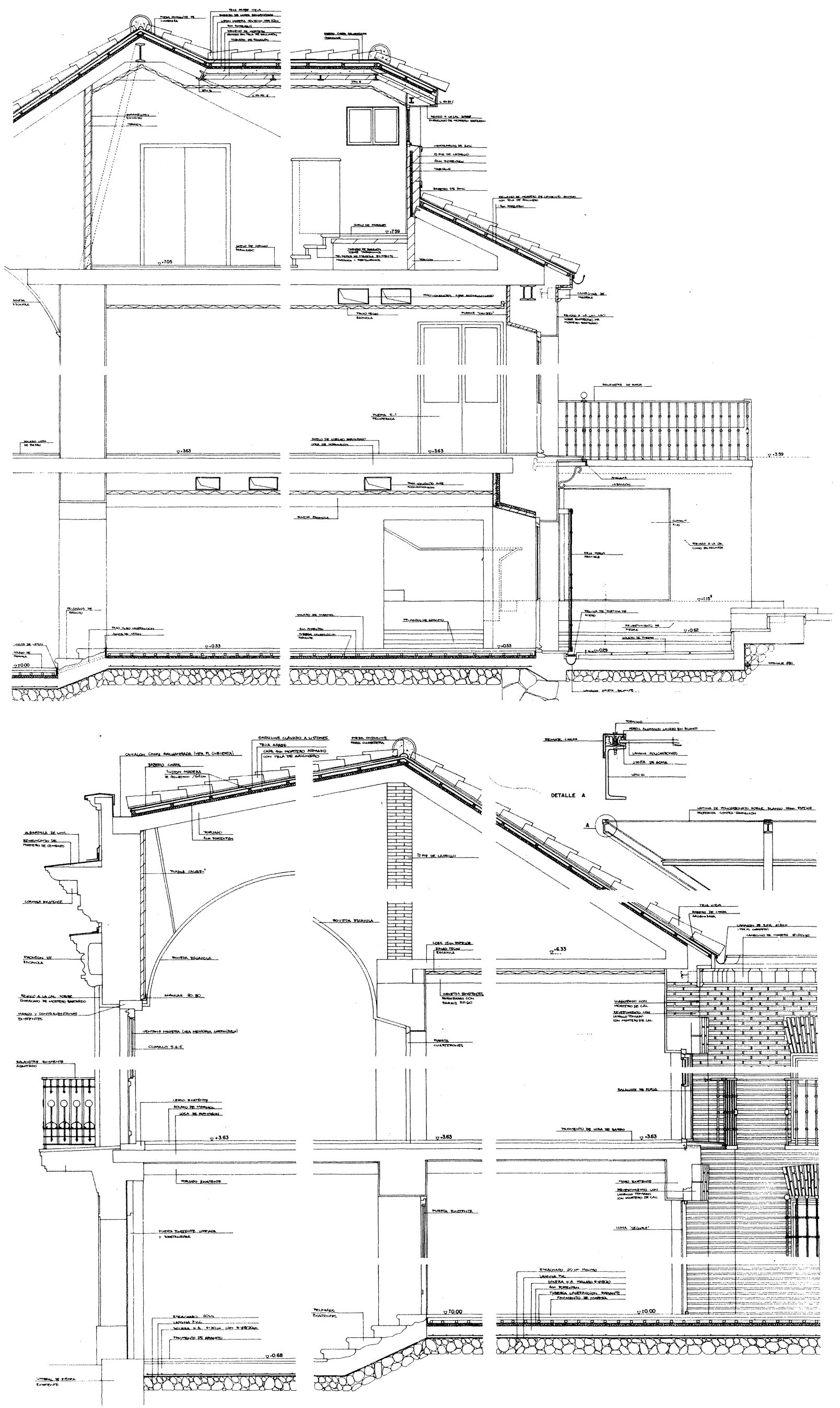


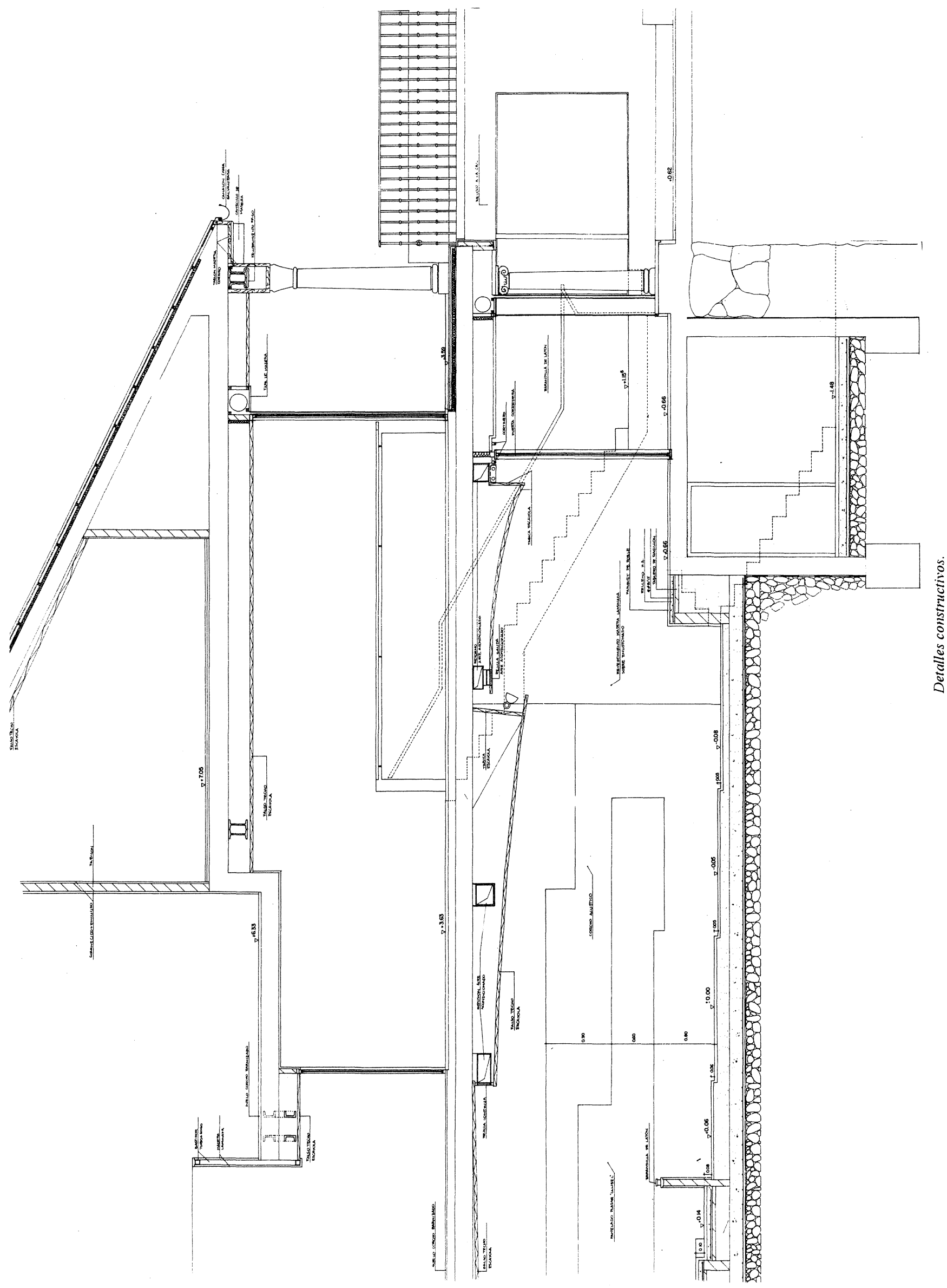


Finalmente, se realizó una calefacción que, en los accesos de laplantabaja, era radiante de aguacon tubode poliestireno reticulado sin juntas, aislada con $4 \mathrm{~cm}$ de poliestireno expandido, siendo, en el resto del edificio, de aire caliente en invierno y acondicionado en verano. La producción de calefacción se realizó con una caldera; la del aire acondicionado con una planta enfriadora situada en el jardín del edificio. La climatología de Guadalajara desaconsejó fuertemente el uso de bombas de calor.

\section{La obra}

Como siempre ocurre con las obras de reforma, durante la construcción aparecieron muchas y desagradables sorpre- sas: muros, aparentemente de fábrica, que eran de tapial, con enormes fisuras debidas a viejos asientos, cuevas bajo muros de carga, venas de agua y cargaderos desconocidos que, inexplicablemente, soportaban muros de carga que, a su vez, soportaban una cubierta en una condiciones deplorables.Todo se fue reforzando cuidadosamente y estabilizando con recalzos, muros de hormigón, reformas de estructura (como la muy complicada "F-2" del plano 6) y con la inestimable ayuda de los hermanos Viejo, responsables y minuciosos constructores. Se ha preferido mostrar los planos, tal y como quedaron al final de la obra, con las múltiples reformas, raspaduras y retoques que fueron necesitando, a medida que se iba reformando el edificio.

\title{
Publicación del Instituto Eduardo Torroja - CSIC
}

\author{
Número monográfico de INFORMES
}

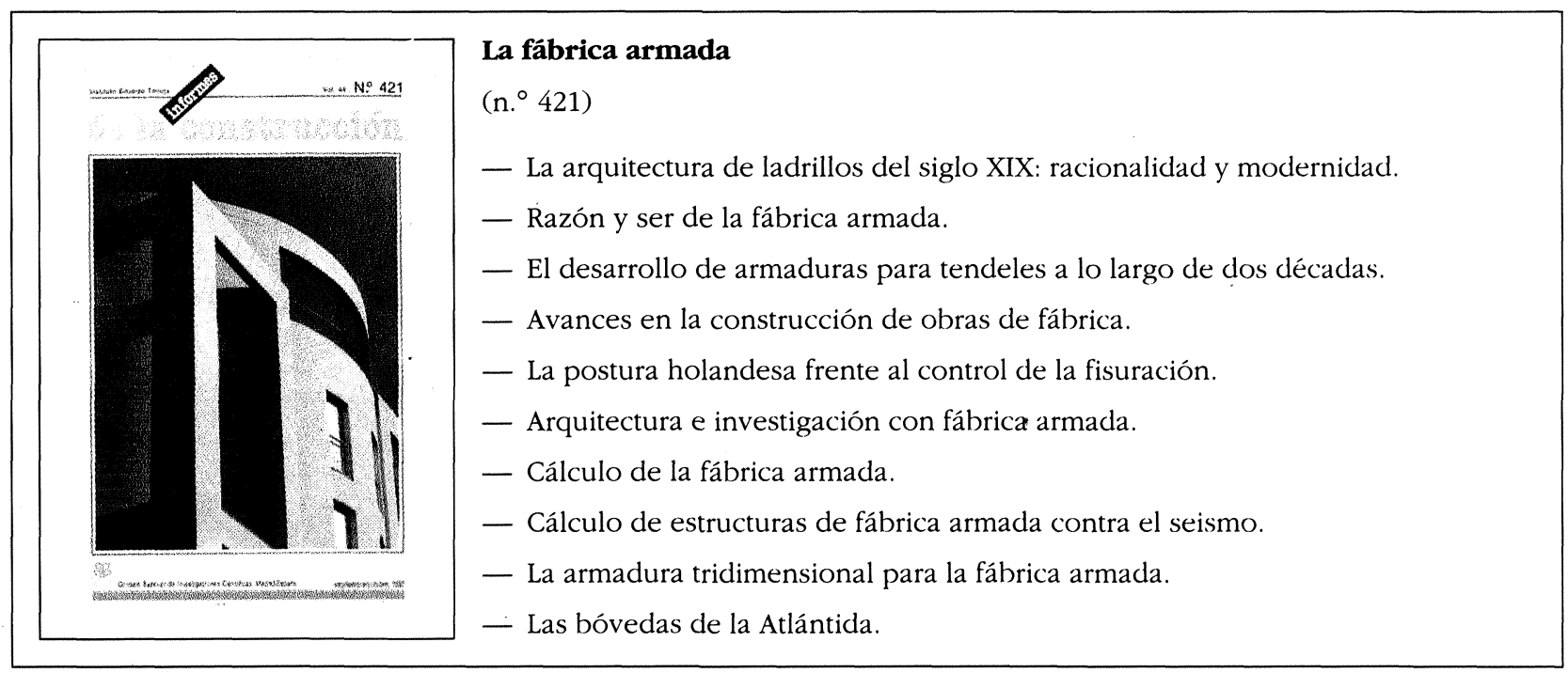

